\title{
EFFECT OF INHIBITION OF STERCULIA FOETIDA LEAVES ON MILD STEEL IN HYDROCHLORIC ACID
}

\author{
M. J. Judithaa, R. Jeevitha and A. P. Srikanth* \\ Department of Chemistry, Government Arts College (Autonomous), \\ Coimbatore, Tamil Nadu, India. \\ *E-mail: apsrikanth8@gmail.com
}

\begin{abstract}
The effect of inhibition on mild steel in an aggressive medium could be studied using sterculia foetida leaves (SFL) which were used as a green inhibitor. The inhibiting effect was analyzed by mass loss method with various times of immersion at different temperatures. By increasing the concentration of the plant extract as well the immersion time the inhibition efficiency increases. The corrosion inhibitive nature of the (SFL) extract was confirmed from the increasing charge transfer resistance value in the electrochemical impedance spectroscopy. In the potentiodynamic polarization technique, both the cathodic and anodic reactions were controlled. The protective film formed on the surface of the metal acted as a barrier against corrosion which was proved from scanning electron microscopic analysis.

Keywords: Corrosion, Inhibitors, Sterculia foetida, Potentiodynamic Polarization, Electrochemical Impedance Spectroscopy, Charge Transfer Resistance.
\end{abstract}

(C) RASĀYAN. All rights reserved

\section{INTRODUCTION}

The detrimental attack which has been taking place on the metal due to the environmental change is called corrosion. It is caused because of the instability in the thermodynamic specifications. The outstanding materials mainly used in industries are mild steel and iron which are less resistant to corrosion. The most important factor that affects the corrosion is the temperature. In most of the industries, the corrosive agents are used for the descaling process at higher temperature ${ }^{17}$. Corrosion is the major threat to the economic status of our nation which should be controlled. It can be minimized by using corrosion-resistant materials, protective coatings and the use of inhibitors. Although many preventive measures are in use, the role played by the corrosion resistants is a sensible approach to restraint the deterioration process ${ }^{16}$. The organic inhibitors are mainly used due to the presence of heteroatoms such as oxygen, nitrogen and sulphur where the lone pair of electrons present on the heteroatoms can hinder the process of corrosion. There are two types of organic inhibitors namely natural and synthetic organic inhibitors. The natural inhibitors are otherwise called as Green inhibitors which are ecofriendly as well as less expensive compared to the synthesized organic inhibitors. Based on these, plant extracts are selected as corrosion inhibitors due to low cost, non-toxicity, biodegradability and easy availability ${ }^{1}$.

\section{Preparation of Mild Steel Specimen}

Rectangular samples of area $(2 \times 5 \times 0.2 \mathrm{~cm})$ were being cut from a giant mass of mild steel. The mild steel stripes were intuitively refined. The cylindrically made electrode which was Teflon coated acted as the working electrode. The electrode was used to carry over the studies such as Electrochemical impedance spectroscopy and potentiodynamic polarization techniques.

\section{Preparation of the Plant Extract}

The SterculiaFoetida leaves were collected, washed, dried, dappled for two weeks and powdered. The plant extract was prepared using a reflux condenser by mixing $25 \mathrm{~g}$ of the powdered sample with $500 \mathrm{ml}$ of

Rasayan J. Chem., 13(2), 1144-1152(2020)

http://dx.doi.org/10.31788/RJC.2020.1325456 
the doubly distilled water, kept in a water bath for 3hours and kept overnight. The solution was made up to $500 \mathrm{ml}$ after filtration. The stock solution was used to prepare different concentrations.

\section{Weight Loss Method}

\section{EXPERIMENTAL}

The mass loss measurement was carried out by immersing MS specimens in various concentrations as well as a blank solution for $24 \mathrm{hrs}$. After that, the coupons were cleaned and the weight loss could be found out. The experiment was repeated and the average value was taken for calculation purposes. From the reports, the corrosion rate and inhibition efficiency were calculated using the following relation:

$$
\begin{aligned}
\text { CR (mmpy) } & =\frac{K X W}{D X A X t} \\
\text { Where } \mathrm{k} & =8.76 \times 10^{4} \\
\mathrm{D} & =\text { Density in gm } / \mathrm{cm}^{3} \\
\mathrm{~W} & =\text { Weight loss in grams } \\
\mathrm{A} & =\text { Area in } \mathrm{cm}^{2} \\
\mathrm{t} & =\text { Time in hours } \\
\mathrm{IE} \% & =\frac{W_{0}-W_{i}}{W_{i}} \times 100
\end{aligned}
$$

Where, $\mathrm{W}_{0}$ and $\mathrm{W}_{\mathrm{i}}$ were the weight loss of uninhibited and inhibited MS specimens.

\section{FTIR Analysis}

The sterculia foetida leaves in the powdered form were exposed towards the infrared rays resulted in the transmittance and reflectance of IR rays at various frequencies was transformed into absorption peaks. Using these spectral bands various functional groups could be found out which were present in the leaves ${ }^{2}$.

\section{Scanning Electron Microscopy}

A scanning electron microscopic survey could be conducted for the mild steel specimen using MIRA3 TESCAN $^{3}$. The protective film was formed on the corroded surface by dipping MS specimen in the optimum concentration.

\section{Effect of Temperature}

The inhibition efficiency and corrosion rate at different temperatures were analyzed using a weight-loss method by suspending the MS stripes in the presence and absence of the inhibitor in acid medium with different temperatures ranging from $313 \mathrm{k}$ to $353 \mathrm{k}$ for 2 hours time duration.

\section{Electrochemical Methods}

Potentiodynamic polarization study and $\mathrm{AC}$ impedance were brought about using $\mathrm{CH}$ instrument model 680 Amp Booster. It was made up of three-electrode cell arrangement. The three electrodes were platinum electrode, saturated calomel electrode and MS rod coated with Teflon as the working electrode. For the EIS measurement, the frequency range was fixed to be 1 to $10000 \mathrm{HZ}$ and for the PDP the potential range was fixed between $-250 \mathrm{mV}$ to $-750 \mathrm{mV}$.

\section{UV-Visible Spectrophotometer}

The plant extract and the product obtained as a result of the corrosion process were subjected to UVVisible spectrophotometric analysis in the wavelength range of $200-750 \mathrm{~nm}$ using Agilent technologies Cary 8454/ UV -Visible spectrophotometer.

\section{Weight Loss Method}

\section{RESULTS AND DISCUSSION}

The mass loss measurements could be conducted by varying the concentrations of SFL extract. It was evident from the (Table-1) that there was a decrement in the corrosion rate by increasing the concentration of the plant extract and thereby reached maximal value at an optimum concentration of $25 \mathrm{ml}$. The protective film which acted as a barrier between the mild steel surface and the corrosive environment was formed thereby blocked the active sites. ${ }^{4}$ 
RASĀYAN J. Chem.

Vol. 13 | No. 2 |1144 - 1152| April - June | 2020

Table-1: Mass Loss Measurement of MS in Different Concentrations of SFL Extract in Acid Medium

\section{FTIR Spectroscopy}

\begin{tabular}{c|c|c}
\hline $\begin{array}{c}\text { Conc of } S F L \\
(\mathrm{ml})\end{array}$ & $\begin{array}{c}\text { CR } \\
(\mathrm{mmpy})\end{array}$ & IE (\%) \\
\hline Blank & 405.14 & $*$ \\
\hline 5 & 124.59 & 69.25 \\
\hline 10 & 101.37 & 74.98 \\
\hline 15 & 75.72 & 81.31 \\
\hline 20 & 53.38 & 86.82 \\
\hline 25 & 28.26 & 93.02 \\
\hline
\end{tabular}

The various functional groups present and how the inhibitor got adsorbed on the MS specimen were analyzed using IR spectroscopy. The corresponding band at $3349.39 \mathrm{~cm}^{-1}$ indicated the presence of $-\mathrm{OH}$ stretching frequency of alcohol. The existence of peaks at $2921 \mathrm{~cm}^{-1}$ and $2854 \mathrm{~cm}^{-1}$ reffered the C-H single bond group of alkanes. ${ }^{2}$ The appearance of either the carbonyl group or $\mathrm{C}-\mathrm{O}-\mathrm{C}$ link or $\mathrm{C}=\mathrm{C}$ link was proved by the existence of the band at $1630.32 \mathrm{~cm}^{-15}$. The absorption bands at the frequencies of $1440.48 \mathrm{~cm}^{-1}$ and $1243.39 \mathrm{~cm}^{-1}$ were due to $\mathrm{C}-\mathrm{H}$ bending in $\mathrm{CH}_{3}$ or $-\mathrm{OH}$ bending vibration and $\mathrm{C}-\mathrm{O}$ stretching vibration. ${ }^{6}$ The band at $1058.33 \mathrm{~cm}^{-1}$ referred to the $\mathrm{C}-\mathrm{O}$ stretching frequency. Some of the absorption bands below $1000 \mathrm{~cm}^{-1}$ were due to aliphatic $-\mathrm{CH}$ group ${ }^{7}$. As per the above-said information, there was the possibility of the formation of the metal-inhibitor bond which helped to improve the inhibition efficiency in favor of adsorption ${ }^{8}$. There was the domination of the corrosion controlling mechanism by increasing the concentration of the plant extract. The oxygen and nitrogen atoms present in the phytochemical of the plant extract helped to control the corrosion by donating the lone pair of electrons present in it $^{2}$.

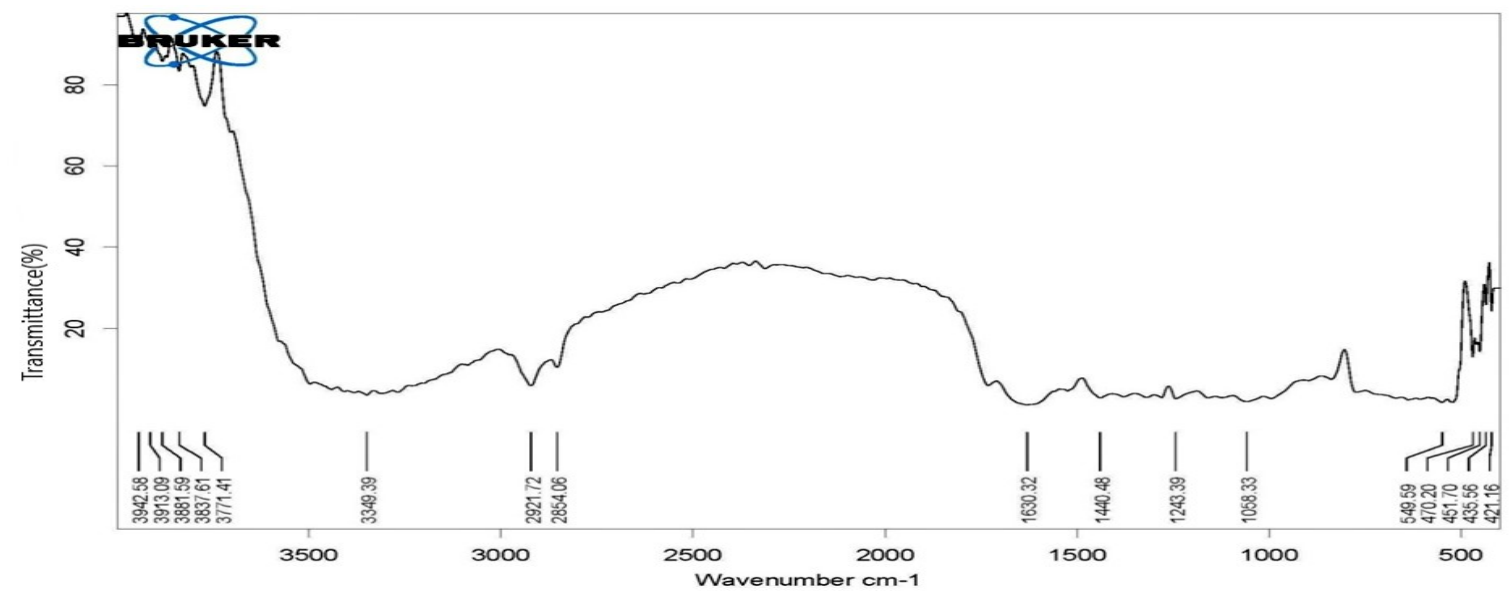

\section{Effect of Immersion Time}

Fig.-1: FT-IR Spectra of SFL Plant Extract

Using the weight loss measurement, the various immersion time analysis was carried out for MS specimens in the aggressive medium with and without the plant extract at room temperature. It would be explained in (Table-2) that the corrosion of the metal was decreased as the concentration of the inhibitor was increased compared to the blank. It was cleared that the increase in the inhibition efficiency is due to the adsorption of secondary metabolites on the MS surface, which is present in the extract ${ }^{9}$.

Table-2: Variation in Immersion Time

\begin{tabular}{c|c|c|c|c|c|c|c}
\hline Conc. of & \multicolumn{7}{|c}{ Percentage of Inhibition Efficiency } \\
\cline { 2 - 8 } SFL $(\mathrm{ml})$ & $1 \mathrm{~h}$ & $3 \mathrm{~h}$ & $5 \mathrm{~h}$ & $7 \mathrm{~h}$ & $9 \mathrm{~h}$ & $12 \mathrm{~h}$ & $24 \mathrm{~h}$ \\
\hline 5 & 38.96 & 45.17 & 57.28 & 60.56 & 65.53 & 70.07 & 80.03 \\
\hline 10 & 48.75 & 54.92 & 65.94 & 66.5 & 68.87 & 75.85 & 84.31 \\
\hline 15 & 49.8 & 64.41 & 71.45 & 73.53 & 76.74 & 80.8 & 87.93 \\
\hline 20 & 60.21 & 68.78 & 74 & 77.73 & 81.06 & 85.12 & 88.47 \\
\hline 25 & 63.16 & 70.23 & 78.28 & 81.51 & 85.51 & 87.69 & 92.96 \\
\hline
\end{tabular}

1146 
RASĀYAN J. Chem.

Vol. 13 | No. 2 |1144 - 1152| April - June | 2020

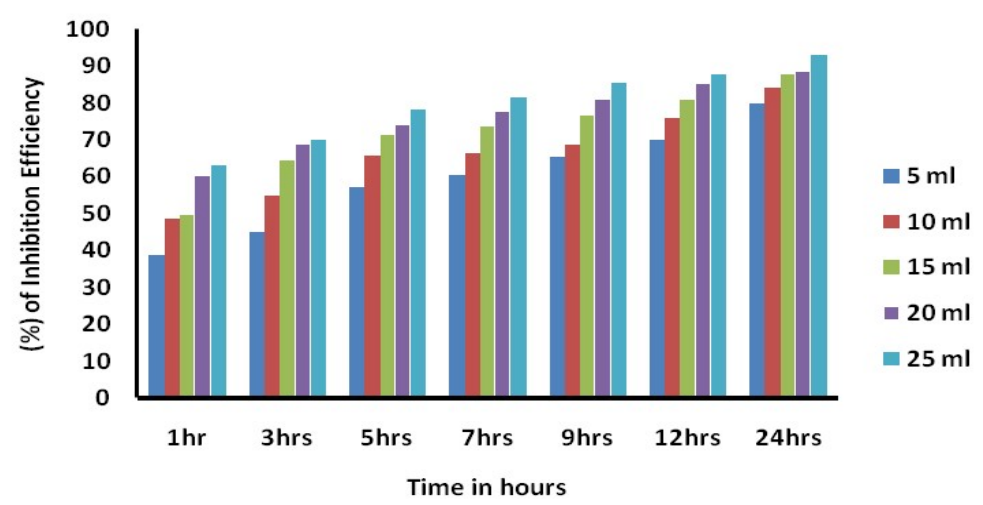

Fig.-2:Vartiation in Immersion Time

\section{Potentiodynamic Polarization}

The potentiodynamic polarization studies dealt with the kinetics of cathodic and anodic reactions. From the (Fig.-3). it was evident that the active sites for the corrosion to occur were minimized because both the Tafel curves showed deviation in the lower current density region. As the concentration of the plant extract was increasing, there was the suppression in the cathodic and anodic reactions thereby enhanced the corrosion inhibition efficiency. There were some shifts in the potentials towards the anodic and cathodic region exhibited by the polarization curves when compared with the blank solution. The abovesaid information revealed that the plant extract blocked the active sites of the surface of the steel and caused an increase in inhibition efficiency. It could also be revealed that the plant extract hinders the interaction over MS specimens and modifying the cathodic and anodic reactions ${ }^{15}$. This was attributed that the surface coverage was increased because the plant extract gets adsorbed above the surface of the sample ${ }^{10}$. The optimum concentration was found to be $25 \mathrm{ml}$. The inhibition efficiency is calculated using the following formula,

$$
\mathrm{IE} \%=\frac{\text { Icor (Blank) }- \text { Icorr(inh) }}{\text { Icor (Blank) }} \times 100
$$

Where, $\mathrm{I}_{\text {corr(inh) }}$ and $\mathrm{I}_{\text {corr(Blank) }}$ are corrosion current with and without the inhibitor. ${ }^{11}$

Table-3: Electrochemical Polarization Parameters of MS Dipped in Various Concentrations of Plant Extract in Corrosive Media

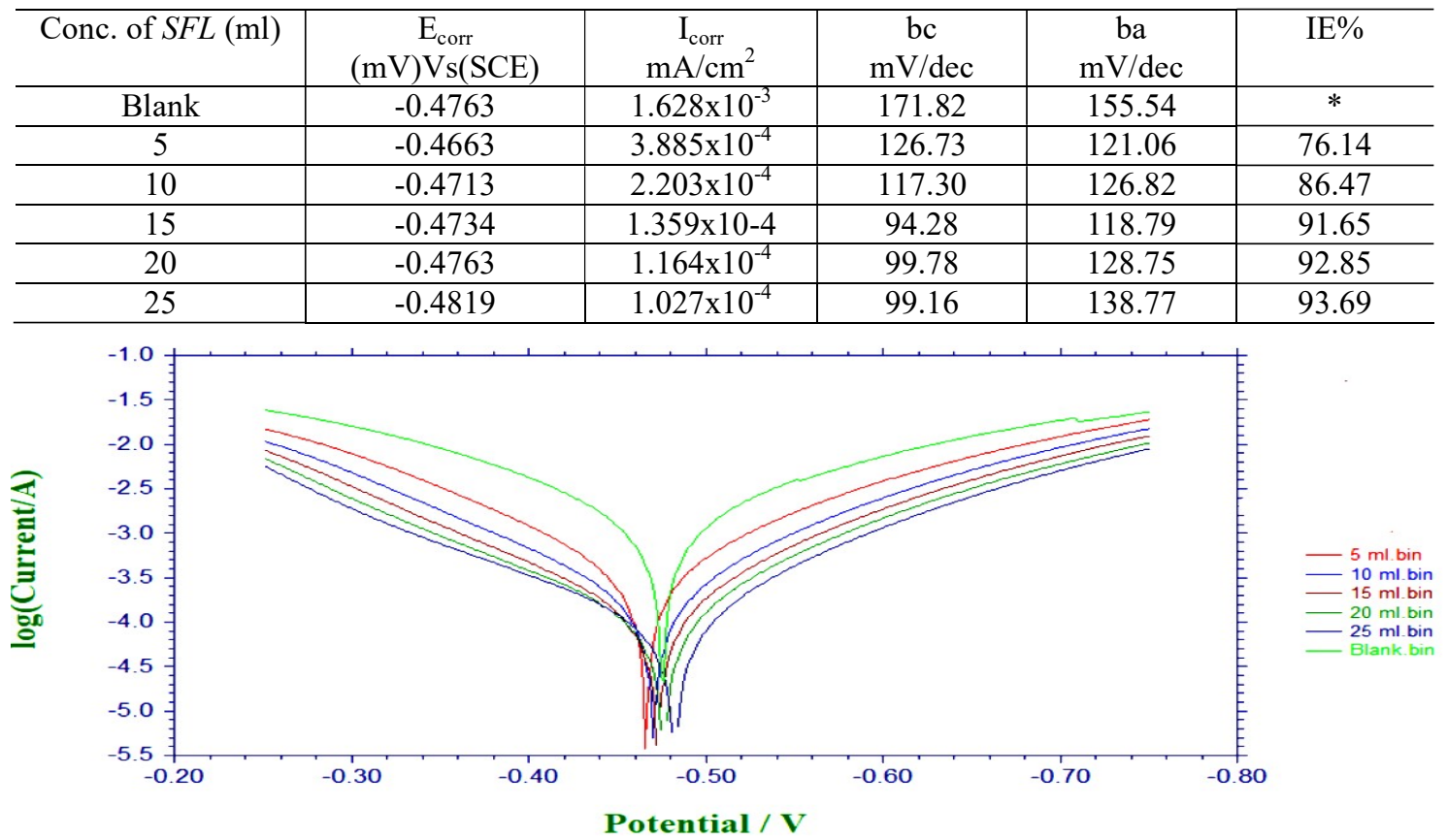

Fig.-3: Electrochemical Polarization Graph of MS in Presence and Absence of SFL Extract. 
RASĀYAN J. Chem.

Vol. 13 | No. 2 |1144 - 1152| April - June | 2020

\section{Electrochemical Impedance Spectroscopy}

From the (Fig.-4) it was understood that the single semicircle loop was observed, which was indicating that in the aggressive medium the mild steel got corroded due to the charge transfer phenomena. By coming across the Nyquist plot it was clearly shown that the diameter was found to be higher by increasing the concentration of the plant extract which witnessed that the corrosion of the MS was subsided by forming a protective coating over the surface of the stripes ${ }^{11}$. The $\mathrm{C}_{\mathrm{dl}}$ values in the descending order proved that the thickening of the electrical double layer was increased as well as a decrease in the dielectric constant has taken place. Based on all the above-said information the inhibition efficiency could be calculated using the formula:

$$
\mathrm{IE} \%=\frac{\text { Rct(inh) }- \text { Rct(Blank) }}{\text { Rct(Blank })} \times 100
$$

Where, $\mathrm{R}_{\mathrm{ct}(\mathrm{in})}$ and $\mathrm{R}_{\mathrm{ct}(\mathrm{B})}$ are inhibited and uninhibited values of charge transfer resistance.

Table-4: Measurement of Impedence for the Mild Steel Specimen with Various Concentrations of Plant Extract in $1 \mathrm{~N} \mathrm{HCl}$

\begin{tabular}{c|c|c|c}
\hline $\begin{array}{c}\text { Conc. of } \\
S F L(\mathrm{ml})\end{array}$ & $\begin{array}{c}\mathrm{C}_{\mathrm{dl}} \\
\left(\mu \mathrm{Fcm}^{-2}\right)\end{array}$ & $\begin{array}{c}\mathrm{R}_{\mathrm{ct}} \\
\Omega \mathrm{cm}^{2}\end{array}$ & $\mathrm{IE} \%$ \\
\hline Blank & $7.295 \times 10^{-5}$ & 16.24 & $*$ \\
\hline 5 & $6.386 \times 10^{-5}$ & 49.07 & 66.90 \\
\hline 10 & $5.74 \times 10^{-5}$ & 97.65 & 83.37 \\
\hline 15 & $5.318 \times 10^{-5}$ & 143.2 & 88.66 \\
\hline 20 & $5.032 \times 10^{-5}$ & 179.2 & 90.94 \\
\hline 25 & $4.498 \times 10^{-5}$ & 212.5 & 92.36 \\
\hline
\end{tabular}

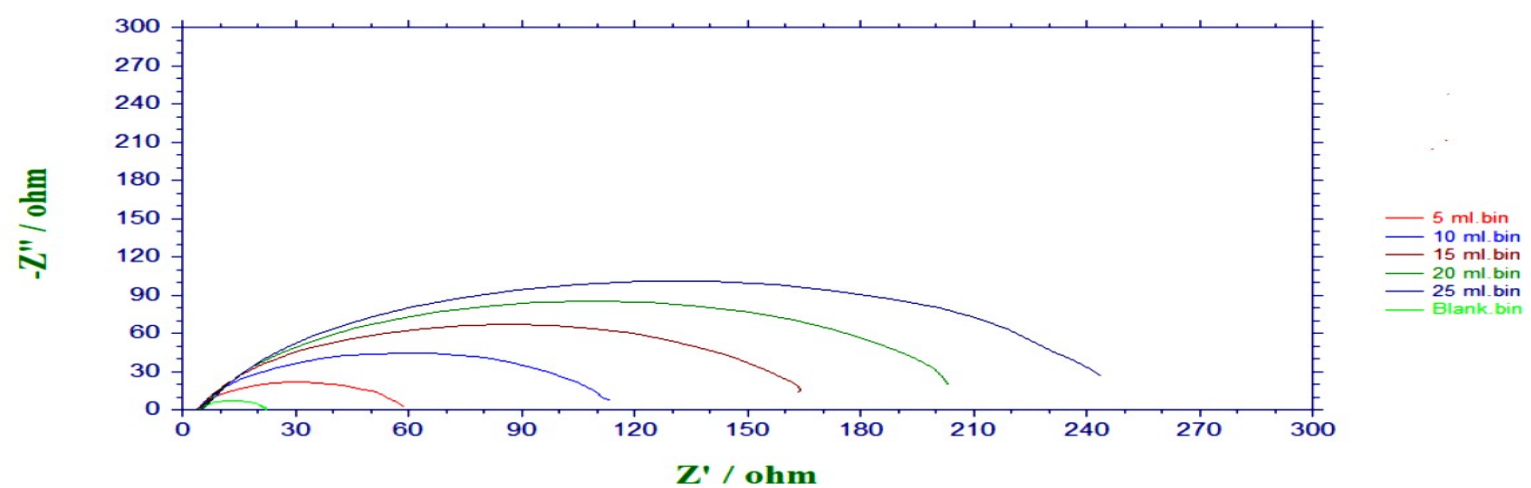

Fig.-4: Nyquist Plot of Electrochemical Impedence Spectroscopy in Uninhibited and Inhibited Solution.

\section{Variation in Temperature}

The effect of temperature on the MS specimen could be studied by varying the temperatures from $313 \mathrm{~K}$ to $353 \mathrm{~K}$ in 2 hours time duration. It was mentioned in the (Table-5) that by increasing SFL extract concentration, the corrosion rate started to decrease as the temperature was increased till $343 \mathrm{~K}$ which was stabilized to $99.59 \%$. This concluded that the plant extract was desorbed at elevated temperatures which were delineated in the (Table-5). ${ }^{12}$

Table-5: Temperature Study of SFl Extract in Various Concentrations

\begin{tabular}{|c|c|c|c|c|c|c|c|c|c|c|}
\hline \multirow{2}{*}{$\begin{array}{l}\text { Conc. of } \\
\text { SFL(ml) }\end{array}$} & \multicolumn{2}{|c|}{$313 \mathrm{~K}$} & \multicolumn{2}{|c|}{$323 \mathrm{~K}$} & \multicolumn{2}{|c|}{$333 \mathrm{~K}$} & \multicolumn{2}{|c|}{$343 \mathrm{~K}$} & \multicolumn{2}{|c|}{$353 \mathrm{~K}$} \\
\hline & $\mathrm{CR}$ & IE & $\mathrm{CR}$ & $\mathrm{IE}$ & $\mathrm{CR}$ & $\mathrm{IE}$ & $\mathrm{CR}$ & IE & $\mathrm{CR}$ & IE \\
\hline Blank & 477.15 & $*$ & 557.95 & * & 816.37 & $*$ & 1152.11 & $*$ & 1593.74 & $*$ \\
\hline 5 & 94.73 & 80.15 & 101 & 81.9 & 96.12 & 88.22 & 79.41 & 93.1 & 509.19 & 68.05 \\
\hline 10 & 84.98 & 82.19 & 80.1 & 85.64 & 92.64 & 88.63 & 73.83 & 93.5 & 195.04 & 87.76 \\
\hline 15 & 68.96 & 85.55 & 68.26 & 87.76 & 80.1 & 90.18 & 72.44 & 93.59 & 175.53 & 88.98 \\
\hline 20 & 53.63 & 89.64 & 55.72 & 90.01 & 79.41 & 90.27 & 45.97 & 96.01 & 149.06 & 90.64 \\
\hline 25 & 42.49 & 91.1 & 41.1 & 92.63 & 59.21 & 92.74 & 4.88 & 99.59 & 95.43 & 94.01 \\
\hline
\end{tabular}


RASĀYAN J. Chem.

Vol. 13 | No. 2 |1144 - 1152| April - June | 2020

\section{Adsorption Isotherm}

The correlation between the MS specimen dipped in pickling solution alone as well as pickling solution with an inhibitor molecule could be studied with the help of adsorption isotherm. The weight-loss method was chosen to select the best adsorption method where the sample fits properly. Efforts were taken to evaluate in various isotherms such as Langmuir, Frumkin, Temkin and Freundlich isotherms. The sample which was taken best fit into the Langmuir adsorption isotherm ${ }^{1}$. Because the $\mathrm{R}^{2}$ value is found to be 0.998 to 0.997 from the temperature $313 \mathrm{~K}$ to $353 \mathrm{~K}$ and a straight line was observed in the graph.

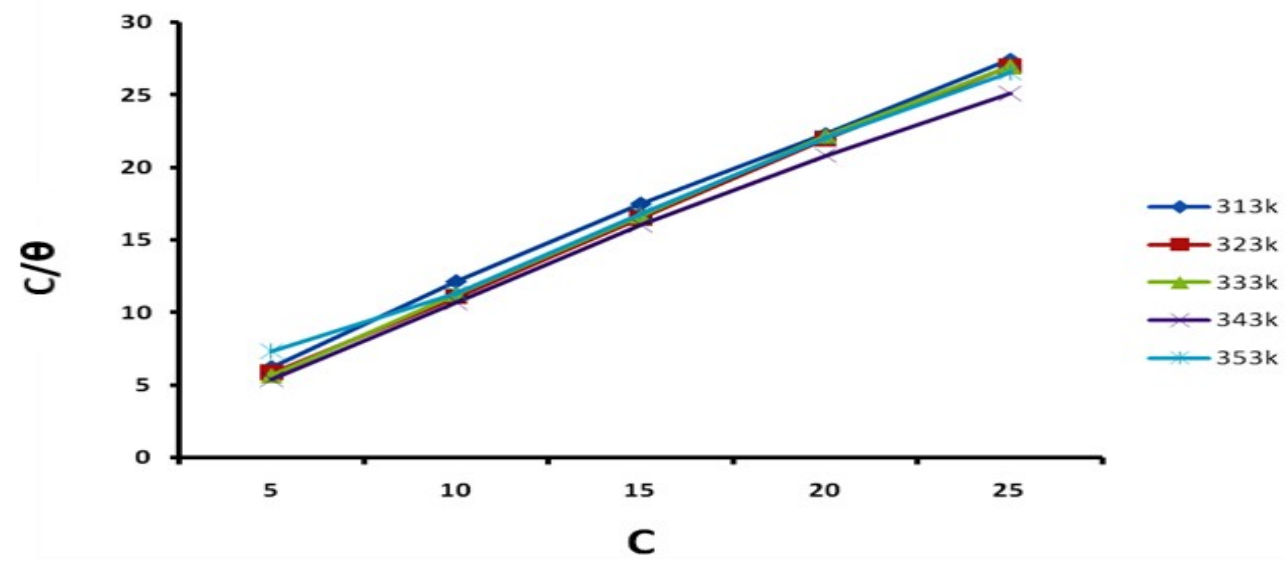

Fig.-5: Langmuir Adsorption Isotherm of Mild steel with SFL extract.

\section{Synergistic Effect}

The inhibition efficiency of $.01 \mathrm{M} \mathrm{KCl}, \mathrm{KBr}$ and $\mathrm{KI}$ were found to be less which was calculated by weight loss measurement technique. In (Table-6) it was clearly stated that the IE\% for halide ions also with inhibitor were higher than the IE\% for the halide ions and inhibitor separately, where synergism has taken place $^{13}$. The synergism parameter $\mathrm{S}_{\theta}$ was calculated by the following equation: ${ }^{14}$

Where,

$$
\mathrm{S}_{\theta}=\frac{1-\theta_{1+2}}{1-\theta_{1+2}^{\prime}}
$$

$\theta_{1} \quad=$ Surface coverage by halide ion.

$\theta_{2} \quad=$ Surface coverage by plant extract.

$\theta^{\prime}{ }_{1+2}=$ Surface coverage by the combination of halide ion and plant extract.

Based on the values obtained for $\mathrm{S}_{\theta}$ three conditions may be possible.

1. If $\mathrm{S}_{\theta}=0$ there is no interaction between the inhibitor compounds

2. If $S_{\theta}>1$ it enhances the synergistic effect.

3. If $\mathrm{S}_{\theta}<1$ there exists the Antagonistic effect.

The synergistic parameters studied for various concentrations of $S F L$ extract with $\mathrm{KCl}, \mathrm{KBr}$ and $\mathrm{KI}$ separately were shown in (Table-6). It was apparent that there would be raise in the inhibiting action due to the addition of the halide ions as well as the synergistic parameter $\mathrm{S}_{\theta}$ which was calculated would be greater than unity proved the synergistic nature of the leaves extract ${ }^{13}$.

\begin{tabular}{c|c|c|c|c|c|c|c}
\multicolumn{2}{c}{ Table-6: Synergistic Parameters of MS Specimen in Various Concentrations of Plant Extract } \\
\hline $\begin{array}{c}\text { Conc. of } \\
\text { SFL }(\mathrm{ml})\end{array}$ & IE\% without & \multicolumn{2}{|c|}{$\mathrm{KCl}$} & \multicolumn{2}{c}{$\mathrm{KBr}$} & \multicolumn{3}{c}{ KI } \\
\cline { 3 - 8 } & Halide Ion & $\mathrm{IE}^{2}$ & $\mathrm{~S}_{\theta}$ & $\mathrm{IE} \%$ & $\mathrm{~S}_{\theta}$ & IE\% & $\mathrm{S}_{\theta}$ \\
\hline 5 & 45.17 & 67.54 & 1.48 & 69.04 & 1.48 & 72.59 & 1.59 \\
\hline 10 & 54.92 & 77.99 & 1.77 & 80.71 & 1.91 & 83.47 & 2.11 \\
\hline 15 & 64.41 & 85.68 & 2.01 & 88.07 & 2.32 & 88.35 & 2.21 \\
\hline 20 & 68.78 & 90.48 & 2.57 & 90.77 & 2.52 & 90.97 & 2.40 \\
\hline 25 & 70.23 & 90.80 & 2.39 & 91.14 & 2.39 & 91.54 & 2.25 \\
\hline
\end{tabular}

\section{UV-Visible Spectroscopy}

The formation of Fe- $S F L$ complex due to the immersion of mild steel stripe in the optimum concentration of $S F L$ extract in the acid medium for $24 \mathrm{hrs}$ was analyzed using UV-Visible spectroscopy. It was 
RASĀYAN J. Chem.

Vol. 13 | No. 2 |1144 - 1152| April - June | 2020

observed that the absorption peaks are due to $n \rightarrow \pi^{*}$ and $\pi \rightarrow \pi^{*}$ transitions. A complex formation has taken place between the metal and the phytochemical constituents which was proved by the absorption spectra $^{12}$.

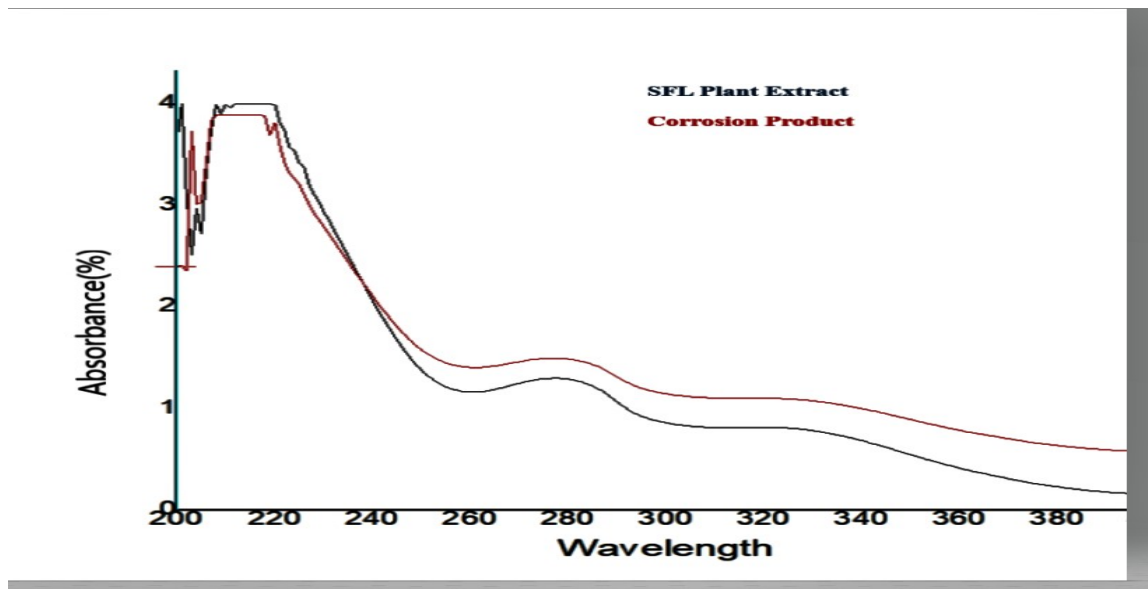

Fig.-6: UV-Visible Spectra of MS in the Presence and Absence of Plant Extract

\section{Study of Surface Morphology}

The study about the surface of the MS stripes which were uninhibited and inhibited using plant extract could be examined using scanning electron microscopy. The surface morphology was studied after the immersion of the stripes in the blank and the plant extract in the acid medium for one day at room temperature. It was obvious from the (Fig.-7a) that the surface was corroded and from the (Fig.-7b) the surface was protected by the formation of a thin layer of protective film which confirmed that a layer was adsorbed on the MS surface.

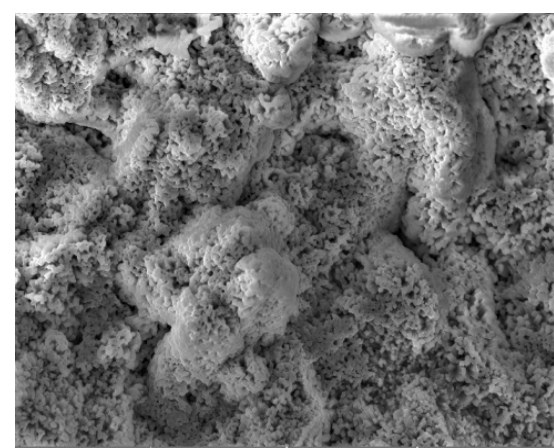

(a)

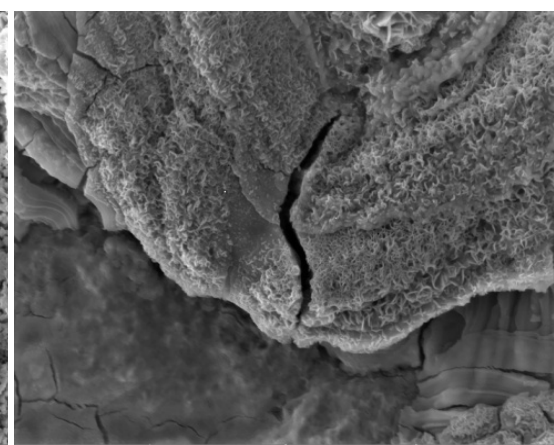

(b)

Fig.-7(a) MS Dipped in 1N HCl and 7(b) MS Dipped in Plant Extract in Acid Medium

\section{EDX Analysis}

The EDX spectra were used to analyze the chemical composition on the surface of the MS specimen in the presence and the absence of the SFL extract in the $\mathrm{HCl}$ medium which was shown in the (Fig.-8)(a) and (b). The MS specimen was dipped in the optimal concentration of $25 \mathrm{ml}$ of $S F L$ extract and the EDX spectra of the immersed sample showed the Fe atomic percentage which was increased to 20.02 compared to the uninhibited sample. This proved that the inhibited mild steel specimen was protected by the formation of protective film over the surface.

Table -7: Element Composition (Atomic \%) of Uninhibited and Inhibited Mild Steel Sample in Corrosive Medium for One Day

\begin{tabular}{c|c|c|c|c|c}
\hline Inhibitors/Elements & $\mathrm{C}$ & $\mathrm{O}$ & $\mathrm{Fe}$ & $\mathrm{Cl}$ & $\mathrm{N}$ \\
\hline Mild Steel in 1N HCl & 9.25 & 71.55 & 15.60 & 3.60 & - \\
\hline Mild Steel in SFL Extract & 11.02 & 68.45 & 20.02 & - & 0.50 \\
\hline
\end{tabular}


RASĀYAN J. Chem.

Vol. 13 | No. 2 |1144 - 1152| April - June | 2020

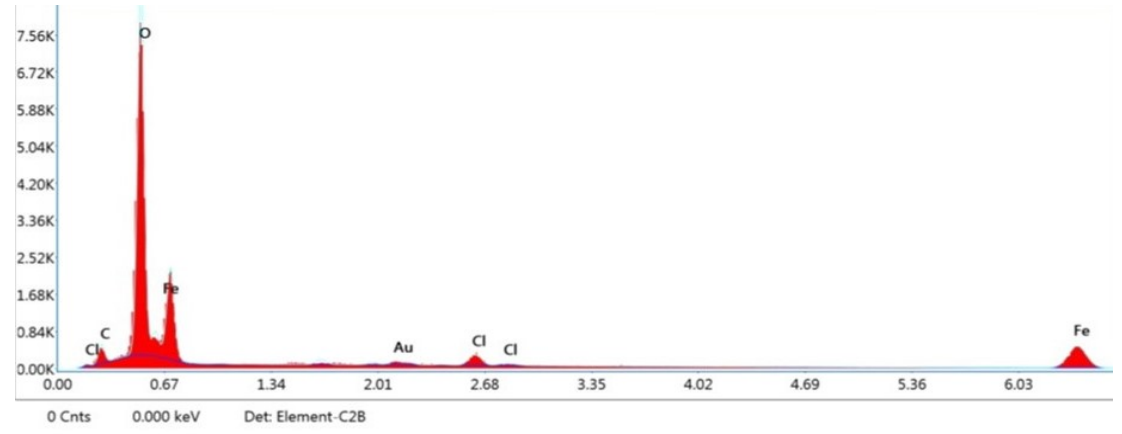

Fig.- 8(a): EDX Spectra of Mild Steel in $1 \mathrm{~N} \mathrm{HCl} \mathrm{Medium}$

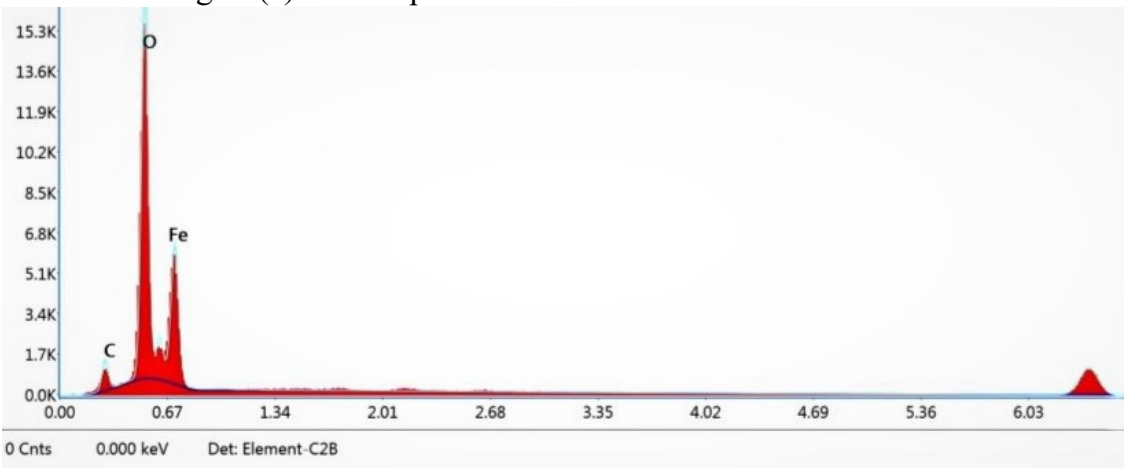

Fig.- 8(b): EDX Spectra of Mild Steel Dipped in SFL Extract in $\mathrm{HCl}$ Medium

\section{CONCLUSION}

As a result of various studies carried out, it was concluded that the $S F$ leaves acted as a good corrosion inhibitor in an aggressive medium which showed the inhibition efficiency of about $93.02 \%$ at an optimum concentration at $25 \mathrm{ml}$. In the temperature studies, chemisorption has taken place till the temperature reaches $343 \mathrm{k}$. In polarization techniques, the cathodic and anodic reactions are retarded which showed that the sterculia foetida leaves extract acted as a mixed type of inhibitor. The SEM and EDX proved that the inhibitor got adsorbed and protects the metal against corrosion. The complex formation between the metal and the phytochemicals present in the plant extract was obvious from the UV-Visible spectroscopy. Due to the addition of halide ions the inhibition efficiency was increased, clearly showed the synergistic nature of the plant extract.

\section{ACKNOWLEDGMENT}

The authors would like to thank the administration and guide, Government Arts College (Autonomous), Coimbatore, for giving his treasured concepts and facilities to carry over the project. We are grateful to the administration of PSG College of Technology and Avinashilingam Institute for Home Science and Higher Education for Women for their assistance.

\section{REFERENCES}

1. D. Jalajaa, S. Jyothi, V. R. Muruganantham and J. Mallika, Rasayan Journal of Chemistry, 12(2), 545(2019), DOI:10.31788/RJC.2019.1224096

2. Roland TolulopeLoto and EbohOghenerukewe, Oriental Journal of Chemistry, 32(5), 2813(2016), DOI: $10.13005 / \mathrm{ojc} / 320557$

3. K. K. Alaneme, S. J. Olusegan, A. W. Alo, Alexandria Engineering Journal, 55(2), 1069(2016), DOI:10.1016/j.aej.2016.03.012

4. D.K. Singh, S. Kumar, G. Udayabhanu, R.P. John, Journal of Molecular Liquids, 216, 738(2016), DOI: $10.1155 / 2016 / 6208937$

5. M.I. Arias-Montoya, G.F. Dominguez-Patiño, J.G. Gonzalez-Rodriguez, J.A. Dominguez-Patiño, M.L. Dominguez-Patiño, Advances in Materials Physics and Chemistry, 5, 447(2015), DOI: $10.4236 / \mathrm{ampc} .2015 .511045$ 
RASĀYAN J. Chem.

Vol. 13 | No. 2 |1144 - 1152| April - June | 2020

6. P. R. Sivakumar, M. Karuppusamy, S.Perumal, A. Elangovan, A.P. Srikanth, Journal of Environmental Nanotechnology, 4(2),31(2015), DOI:10.13074/jent.2015.06.152144

7. M. Ramanandasingh, Prachi Gupta, Kaushal Gupta, Arabian Journal of Chemistry, 52(7),2015, DOI: 10.1016/j.arabjc.2015.01.002

8. O. Benali, H. Benmehdi, O. Hasnaoui, C. Selles, R. Salghi, Journal of Materials and Environmental Science, 4(1), 127(2013)

9. Ghadah M. AL-Senani, Sameerah I. AL-Saeedi and RasmiahAlmufarij, Oriental Journal of Chemistry, 31(4),2077(2015), DOI:10.13005/ojc/310428

10. Yue Meng, Wenbo Ning, Bin Xu, Wenzhong Yang, Kegui Zhang, Yun Chen, Lihua Li, Xi Liu, Jinhong Zhenga and Yimin Zhang, RSC Advances, 7, 43014(2017), DOI:10.1039/c7ra08170g

11. Archana Pandey, B. Singh, Chandrabhan Verma, and Eno. E. Ebenso, RSC Advances, 7, 47148(2017), DOI:10.1039/c7ra08887f

12. R. Thilagavathi, A. Prithiba and R. Rajalakshmi, Rasayan Journal of Chemistry, 12(2), 431(2019), DOI: $10.31788 /$ RJC.2019.1225133

13. K. S. Shaju, K. Joby Thomas, P. Vinod, Raphael and Aby Paul, InternationalScholarly Research Network, 2012, Article ID 425878, DOI:10.5402/2012/425878

14. K. Aramaki and M. Hackerman, Journal of The Electrochemical Society, 116, 568(1969), DOI: $10.5402 / 2012 / 425878$

15. Y. Stiadi, Rahmayeni, L. Rahmawati, M. Efdi, H. Aziz and Emriadi, Rasayan Journal of Chemistry, 13(1),230(2020), DOI:10.31788/RJC.2020.1315325

16. S. Jyothi1, Y.V. Subba Rao and P. S. Samuel Ratnakumar, Rasayan Journal of Chemistry, 12(2), 537(2019), DOI:10.31788/RJC.2019.1225000

17. Yuli Yetri1, Emriadi, Novesar Jamarun and Gunawarman, Rasayan Journal of Chemistry, 9(4), 716(2016)

[RJC-5456/2019] 